\title{
The Impact of Fractional Flow Reserve on Revascularization
}

Islam Y. Elgendy $\cdot$ Calvin Choi $\cdot$ Anthony A. Bavry

To view enhanced content go to www.cardiologytherapy-open.com

Received: August 29, 2015 / Published online: September 30, 2015

(C) The Author(s) 2015. This article is published with open access at Springerlink.com

\section{ABSTRACT}

Introduction: Fractional flow reserve (FFR) is recommended by society guidelines for assessment of the hemodynamic significance of intermediate coronary lesions when non-invasive evidence of myocardial ischemia is unavailable. However, the prevalence of FFR usage in current practice and how FFR values impact revascularization decisions are not well known.

Methods: At a single-center Veterans Administration Hospital, all subjects referred for coronary angiography for any indication from the period from May 2012 until January 2014 were prospectively entered into a database. FFR was measured in all intermediate coronary lesions (30-70\% stenosis). Based on

Electronic supplementary material The online version of this article (doi:10.1007/s40119-015-0051-1) contains supplementary material, which is available to authorized users.

I. Y. Elgendy · C. Choi · A. A. Bavry $(\bowtie)$

Department of Medicine, University of Florida, Gainesville, FL, USA

e-mail: bavryaa@medicine.ufl.edu;

anthony.bavry@va.gov

C. Choi · A. A. Bavry

North Florida/South Georgia Veterans Health

System, Gainesville, FL, USA the FFR results, the lesions were categorized into 3 different groups: FFR $>0.80$ (non-ischemic), FFR $0.75-0.80$ (gray zone), and $\mathrm{FFR}<0.75$ (ischemic).

Results: A total of 1482 cardiac catheterizations were performed during the study period. FFR was performed in 347 (23\%) of these procedures. The total numbers of intermediate coronary lesions evaluated with FFR were 429. The mean FFR value was 0.79 (median $=0.80$; interquartile range 0.64-0.96). Among 211 non-ischemic lesions, revascularization was deferred in 201 (95\%). In the gray-zone group (73 lesions), 35 (48\%) lesions were treated with percutaneous coronary intervention (PCI), 11 (15\%) lesions were referred for coronary artery bypass grafting surgery (CABG), and 27 (37\%) lesions were treated medically. In the ischemic group (145 lesions), 82 (57\%) lesions were treated with PCI, 41 (28\%) lesions were referred for CABG, and 22 (15\%) lesions were treated medically.

Conclusion: At a Veterans Administration Hospital, FFR was performed in approximately one out of four total catheterizations. FFR documented lack of ischemia in about half of the intermediate coronary lesions, and thus 
reduced the need for many revascularization procedures.

Keywords: Coronary angiogram; Fractional flow reserve; Percutaneous coronary intervention; Revascularization

\section{INTRODUCTION}

Assessment of intermediate coronary lesions (30-70\% stenosis) by coronary angiogram has been shown to be a poor predictor of the hemodynamic significance of the lesion [1]. Earlier studies had suggested that fractional flow reserve (FFR)-guided revascularization was superior at reducing major cardiac adverse outcomes when compared with angiogram-guided revascularization [2-4]. The 5-year follow-up of the Fractional Flow Reserve Versus Angiography for Multivessel Evaluation (FAME; Clinicaltrials.gov identifier, NCT00267774) trial demonstrated that an FFR-guided approach is associated with a similar risk of major events but with a lower number of stented arteries and less resource use [5]. FFR assessment during coronary angiography is endorsed by the European Society of Cardiology and the American College of Cardiology for identification of hemodynamically significant lesions when non-invasive evidence of myocardial ischemia is unavailable [6, 7]. Deferral of revascularization is recommended for non-ischemic lesions $[8,9]$. Despite the documented benefits of FFR, some operators may not embrace the frequent use of FFR. This might be especially true in a fee-for-service system, where FFR could result in deferral of revascularization. The Veterans Health System is unique in that there is no financial incentive to perform revascularization procedures. Therefore, at a single-center
Veterans Administration Hospital, our objectives were twofold. The first objective was to determine how frequently FFR was performed. The second objective was to determine how FFR values would impact the performance or deferral of revascularization, especially within the gray zone.

\section{METHODS}

This was a single-center study that prospectively entered all patients referred for cardiac catheterization for any indication at the North Florida/South Georgia Veterans Health System from May 2012 until January 2014 into a database. This database was established to determine the frequency of FFR usage and how FFR values impact revascularization decisions; therefore, baseline characteristics and clinical outcomes were not recorded. Institutional Review Board approval was obtained prior to conducting the study. FFR was defined as a whole cardiac cycle pressure-derived index of the maximum achievable blood flow in a coronary artery with a stenosis expressed as a ratio of maximum achievable blood flow if that artery were normal $[8,10]$. FFR was measured in all intermediate coronary lesions (30-70\% stenosis) using a coronary pressure guide wire (Volcano Corporation; San Diego, CA) at maximal hyperemia induced by peripherally administrated intravenous adenosine $(140 \mu \mathrm{g} /$ $\mathrm{kg} / \mathrm{min}$ for $2 \mathrm{~min}$ ) or regadenoson $(0.4 \mathrm{mg}$ bolus) at operator discretion. Based on the FFR results, the lesions were categorized into three different groups: FFR $>0.80$ (non-ischemic), FFR 0.75-0.80 (gray zone), and $\mathrm{FFR}<0.75$ (ischemic). The decision to defer or proceed with revascularization on the basis of FFR measurement was left to the operator's judgment. 


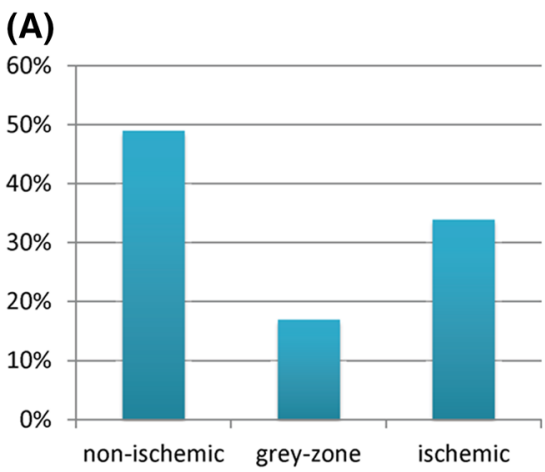

(C)

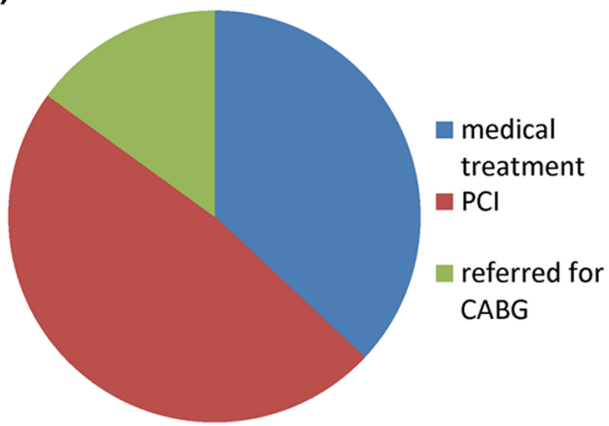

Fig. 1 Summary for the percentage of lesions in each group. a Percentage of lesions in each fractional flow reserve category. Distribution of treatment (medical, revascularization, or referral for CABG) in the non-ischemic group (b),

\section{RESULTS}

A total of 1482 cardiac catheterizations were performed during the study period. FFR was performed in 347 (23\%) of these procedures. The total numbers of intermediate coronary lesions evaluated with FFR were 429 . The mean FFR value was 0.79 (median $=0.80$, interquartile range 0.64-0.96). Among 211 non-ischemic lesions, revascularization was deferred in 201 (95\%). In the remainder of patients with non-ischemic lesions, referral was placed for coronary artery bypass grafting surgery (CABG) for concomitant lesions in eight patients and percutaneous coronary intervention (PCI) was performed in two cases due to intravascular ultrasound findings. In the gray-zone group (73

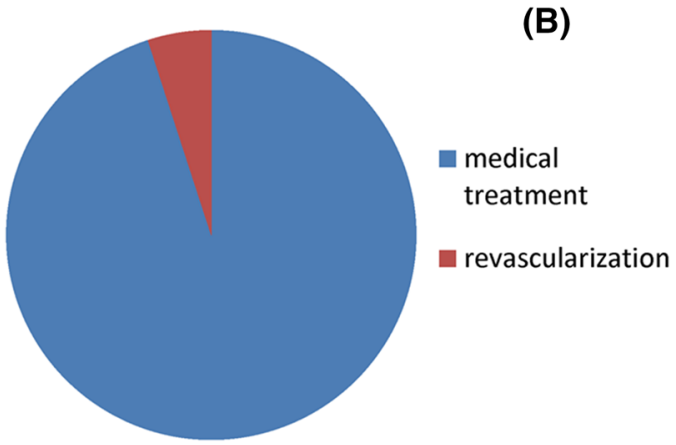

(D)

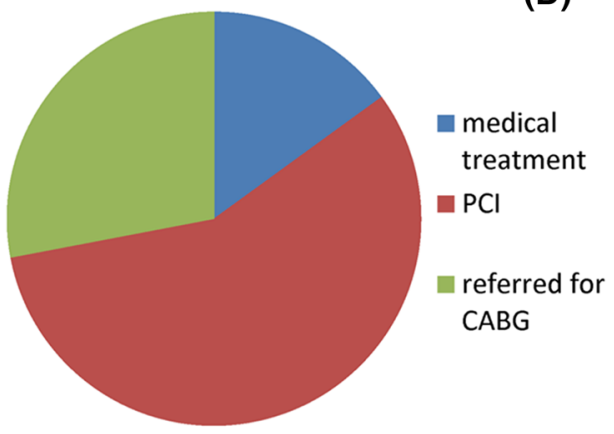

gray-zone group (c), and ischemic group (d). $C A B G$ coronary artery bypass grafting surgery, $P C I$ percutaneous coronary intervention

lesions), 35 (48\%) lesions were treated with PCI, $11(15 \%)$ lesions were referred for CABG, and 27 (37\%) lesions were treated medically. In the ischemic group (145 lesions), 82 (57\%) lesions were treated with PCI, 41 (28\%) lesions were referred for CABG, and 22 (15\%) lesions were treated medically. In the gray-zone group, the most common reasons for deferring revascularization included mild angina symptoms, inadequate anti-angina therapy, or high PCI complexity. In the ischemic group, the most common reasons for deferring revascularization included small vessel size (i.e., $<2.25 \mathrm{~mm}$ ) and/or diffuse lesions that markedly increased the risk for restenosis, or high PCI complexity. Figure 1 summarizes the percentage of lesions in each group. 


\section{DISCUSSION}

In the United States, the average use of FFR has been reported to be as low as $6.1 \%$, with more FFR procedures performed in academic institutions, particularly those with fellowship programs [11]. FFR usage is affected by operator expertise, reimbursement, and the availability of necessary equipment. At our institution, FFR was performed at a higher rate than previously reported; however, as previously mentioned, the Veterans Health System is unique since there is no financial incentive to perform revascularization procedures. Incorporating FFR in revascularization decisions has been demonstrated to result in fewer PCI procedures [2, 12-14]. Our results showed that FFR usage resulted in deferral of revascularization in approximately half of the cases due to non-ischemic lesions.

In the gray-zone group, approximately $63 \%$ of the lesions either underwent PCI or referred for $C A B G$, which is slightly higher than prior studies $[15,16]$. Recent studies had suggested increasing the sensitivity for detecting ischemia (i.e., the threshold for revascularization changed from $\mathrm{FFR}<0.75$ to $<0.80$ ) [4]. We observed that $37 \%$ of gray-zone lesions were deferred revascularization which illustrates that in real-life clinical practice there is still adequate room for medical management and clinical judgment for such lesions. In other words, an FFR value $<0.80$ should not be an 'automatic license' to perform revascularization. Revascularization was deferred in the gray-zone group mostly due to mild symptoms and/or inadequate anti-angina therapy. In the ischemic group, revascularization was deferred infrequently (15\%). This was mostly due to anatomical concerns (characteristics that made PCI high risk or significantly increased the risk for restenosis).
This study was limited by being an observational study conducted in a single academic center. We did not report any baseline characteristics or clinical outcome data; however, this information would not be considered particularly germane to the stated objectives of this study. Moreover, this information can be found in other reports. Meta-analysis of observational studies has documented similar outcomes associated with deferral of non-ischemic left main lesions compared with revascularization of ischemic left main lesions. On the other hand, adverse outcomes are low with deferral of non-ischemic lesions compared with revascularization of ischemic lesions for non-left main lesions [9].

\section{CONCLUSIONS}

In a single-center practice that does not provide a financial incentive for performing revascularization procedures, FFR usage occurred at a higher frequency than previously reported (approximately one in four catheterization procedures). Frequent use of FFR documented lack of ischemia in about half of the intermediate coronary lesions, and thus reduced the need for many revascularization procedures.

\section{ACKNOWLEDGMENTS}

This work was supported by resources provided by the North Florida/South Georgia Veterans Health System (NF/SGVHS). All named authors meet the International Committee of Medical Journal Editors (ICMJE) criteria for authorship for this manuscript, take responsibility for the integrity of the work as a whole, and have given final approval to the version to be published. 
Disclosures. Anthony A. Bavry has received an honorarium from the American College of Cardiology. Islam Y. Elgendy and Calvin Choi have nothing to disclose.

Compliance with ethics guidelines. All procedures followed were in accordance with the ethical standards of the responsible committee on human experimentation (institutional and national) and with the Helsinki Declaration of 1964, as revised in 2013.

Open Access. This article is distributed under the terms of the Creative Commons Attribution-NonCommercial 4.0 International License (http://creativecommons.org/licenses/ by-nc/4.0/), which permits any noncommercial use, distribution, and reproduction in any medium, provided you give appropriate credit to the original author(s) and the source, provide a link to the Creative Commons license, and indicate if changes were made.

\section{REFERENCES}

1. Christou MA, Siontis GC, Katritsis DG, Ioannidis JP. Meta-analysis of fractional flow reserve versus quantitative coronary angiography and noninvasive imaging for evaluation of myocardial ischemia. Am J Cardiol. 2007;99:450-6.

2. Tonino PA, De Bruyne B, Pijls NH, et al. Fractional flow reserve versus angiography for guiding percutaneous coronary intervention. $\mathrm{N}$ Engl J Med. 2009;360:213-24.

3. Pijls NH, van Schaardenburgh P, Manoharan G, et al. Percutaneous coronary intervention of functionally nonsignificant stenosis: 5-year follow-up of the DEFER Study. J Am Coll Cardiol. 2007;49:2105-11.

4. De Bruyne B, Fearon WF, Pijls NH, et al. Fractional flow reserve-guided PCI for stable coronary artery disease. N Engl J Med. 2014;371:1208-17.

5. van Nunen LX, Zimmermann FM, Tonino PA, et al. Fractional flow reserve versus angiography for guidance of PCI in patients with multivessel coronary artery disease (FAME): 5-year follow-up of a randomised controlled trial. Lancet. 2015; doi:10.1016/S0140-6736(15)00057-4.

6. Montalescot G, Sechtem U, Achenbach S, et al. 2013 ESC guidelines on the management of stable coronary artery disease: the Task Force on the management of stable coronary artery disease of the European Society of Cardiology. Eur Heart J. 2013;34:2949-3003.

7. Levine GN, Bates ER, Blankenship JC, et al. 2011 ACCF/AHA/SCAI Guideline for Percutaneous Coronary Intervention. A report of the American College of Cardiology Foundation/American Heart Association Task Force on Practice Guidelines and the Society for Cardiovascular Angiography and Interventions. J Am Coll Cardiol. 2011;58:e44-122.

8. Elgendy IY, Conti CR, Bavry AA. Fractional flow reserve: an updated review. Clin Cardiol. 2014;37:371-80.

9. Bavry AA, Elgendy IY, Petersen JW. Outcomes associated with fractional flow-guided revascularization: a meta-analysis. Clin Cardiol. 2014;37:610-7.

10. Pijls NH, De Bruyne B. Coronary pressure. 2nd ed. The Netherlands: Kluwer Academic Publishers; 2000.

11. Dattilo PB, Prasad A, Honeycutt E, Wang TY, Messenger JC. Contemporary patterns of fractional flow reserve and intravascular ultrasound use among patients undergoing percutaneous coronary intervention in the United States: insights from the National Cardiovascular Data Registry. J Am Coll Cardiol. 2012;60:2337-9.

12. Fröhlich GM, Redwood S, Rakhit R, et al. Long-term survival in patients undergoing percutaneous interventions with or without intracoronary pressure wire guidance or intracoronary ultrasonographic imaging: a large Cohort Study. JAMA Intern Med. 2014;174:1360-6.

13. Van Belle E, Rioufol G, Pouillot C, et al. Outcome impact of coronary revascularization strategy reclassification with fractional flow reserve at time of diagnostic angiography: insights from a large French multicenter fractional flow reserve registry. Circulation. 2014;129:173-85.

14. Curzen N, Rana O, Nicholas Z, et al. Does routine pressure wire assessment influence management strategy at coronary angiography for diagnosis of chest pain?: the RIPCORD Study. Circ Cardiovasc Interv. 2014;7:248-55.

15. Courtis J, Rodés-Cabau J, Larose E, et al. Comparison of medical treatment and coronary 
revascularization in patients with moderate coronary lesions and borderline fractional flow reserve measurements. Catheter Cardiovasc Interv. 2008;71:541-8.

16. Lindstaedt M, Halilcavusogullari Y, Yazar A, et al. Clinical outcome following conservative vs revascularization therapy in patients with stable coronary artery disease and borderline fractional flow reserve measurements. Clin Cardiol. 2010;33:77-83. 